Engineering Sustainability Volume 169 Issue ES3

The paradox of public acceptance of bike sharing in Gothenburg

Nikitas, Wallgren and Rexfelt
Proceedings of the Institution of Civil Engineers Engineering Sustainability 169 June 2016 Issue ES3 Pages 101-113 http://dx.doi.org/10.1680/jensu.14.00070

Paper 1400070

Received 10/12/2014

Published online 26/10/2015

Keywords: town and city planning/transport planning/transport management

Published with permission by the ICE under the CC-BY license.

(http://creativecommons.org/licenses/by/3.0/) i

\title{
The paradox of public acceptance of bike sharing in Gothenburg
}

Alexandros Nikitas MEng, MSc, MA, PhD

Department of Logistics, Operations and Hospitality Management, The Business School, University of Huddersfield, Huddersfield, UK; Division of Design and Human Factors, Department of Product and Production Development, Chalmers University of Technology, Gothenburg, Sweden
Pontus Wallgren BEng, MSc, PhD

Division of Design and Human Factors, Department of Product and Production Development, Chalmers University of Technology, Gothenburg, Sweden

Oskar Rexfelt BEng, MSc, PhD

Division of Design and Human Factors, Department of Product and Production Development, Chalmers University of Technology, Gothenburg, Sweden

Bike sharing is one of the most promising urban planning interventions to facilitate an all-necessary transition towards a more sustainable transport paradigm. Regardless of the fact that hundreds of schemes run in more than 50 countries worldwide, bike sharing is still moderately investigated by research. This paper reports on a primarily quantitative study of $\mathbf{5 5 8}$ responses that was set to frame attitudes reflecting public acceptance towards the rapidly expanding bike-sharing scheme in Gothenburg, Sweden (Styr \& Ställ), in an attempt to identify the 'formula for success'. The respondents generally believed that Styr \& Ställ is a pro-environmental, inexpensive and healthy transport mode, which complements the city's public transport services and promotes a more human-friendly identity for Gothenburg. Even the respondents that self-reported a small (or no) likelihood to use bike sharing were positive towards the scheme. This means that they recognise that bike sharing has a significant pro-social potential and is not a system favouring a particular road-user segment over others that might not be interested or able to use it. The fact that the majority of the respondents do not use the scheme and yet its popularity is still vast indicates that there is much potential for more use in real terms.

\section{Introduction}

Automobility, according to Sheller and Urry (2000), fosters a civil society of hybridised 'car-drivers' that support the transformation of public spaces into flows of traffic, coercing, constraining and unfolding a transport domination in contemporary cities, which has been somewhat downplayed and not dealt with adequately for a number of years. As car use has been linked with increased greenhouse gas emissions, local air and noise pollution, climate change, mortality and morbidity from traffic accidents, chronic diseases, declines in physical activity and obesity (de Nazelle et al., 2011; Vergragt and Brown, 2007), this domination needs to be terminated in favour of a more well-balanced modal share. One of the key steps towards such a transition is replacing a significant proportion of the car use, associated with short inner city trips, with active transportation options such as walking and cycling and with a more frequent use of public transportation. The fact that about half of all car trips, in most of the developed world, are less than 5 miles $(8.05 \mathrm{~km})$ (Maibach et al., 2009) underlines how critical this 'replacement' task is for transport policy-makers and engineers. Nowadays, there are a number of immediate, practical opportunities for urban societies to implement policies and programmes that can promote more sustainable mobility patterns. The implementation of bike-sharing, in particular, is one of the most distinctive practices for inspiring travel behaviour change, since it blends active transportation with public transit.

Bike sharing refers to a locally customised provision of affordable short-term access to bicycles on an 'as-needed' basis that could extend the reach of public transit services to final destinations and be a door opener for increased bicycle usage. More specifically, bike-sharing systems allow people to rent a bicycle at one of the many automatic rental stations scattered around the city, use them for a short journey and return them at any station in the city (Raviv et al., 2013). These systems often use custom-built 'heavy duty' bicycles with non-standard components to reduce theft and typically operate on the basis of a membership or annual fee (Midgley, 2011).

Public bicycles usually contain technologies that allow scheme operators to track movements, from one docking station to the next, and for those with integrated global positioning system (GPS), the bike's movement through the network (Fishman et al., 2013). These data are useful for operators in ensuring an even supply of bicycles and for users to check availability of a bicycle for hire, and a slot for the return of the bicycle (Beroud and Anaya, 2012). Pricing structures generally support short-term usage and favour multiple independent rentals instead of users 
holding on to the same bicycle. For example, in many schemes around the world the first $30 \mathrm{~min}$ (or even one hour) of each bike rental is free, regardless of the number of hires per day; so a user can borrow the bike multiple times in a day for free as long as each bike rental does not exceed the time of the free usage set by the system's operators. After the free rental period eclipses, in most bike-sharing schemes the users are charged on a steeply rising scale. Cyclists that are temporary users of the scheme such as tourists or business-related visitors generally have to provide credit card details, as a deposit to use the scheme.

Bike sharing could also act as a door opener for increased bicycle usage by being a 'living' example or rather a strong 'visual statement' of the fact that bicycles belong to a city's streets. Commuters sharing the same road transport infrastructure could very well see bike sharing as a powerful on-street 'cycling promotion campaign'. Pucher et al. (2010) report that bicycling has increased in cities that have implemented bike-sharing programmes under the note that these results reflect simultaneously the impact of improvements in bicycling facilities implemented at the same time as the bike-sharing programmes. Goodman et al. (2014), on the other hand, make an even more powerful argument, suggesting that one potential way in which cycling may become normalised in low-cycling settings is through the introduction of bicycle-sharing systems. DeMaio (2009) estimates that bike sharing is responsible for raising bike mode share up to $1.5 \%$ in cities with pre-existing low cycling use.

Shaheen et al. (2010) summarise the benefits of bike sharing as flexible mobility, emission reductions, physical activity benefits, reduced congestion and fuel use, individual financial savings and support for multimodal transport connections. The most distinctive function of such a scheme, however, is the concept of 'sharing', as individuals use bicycles on an 'as-needed' basis without the costs and responsibilities of bicycle ownership. This notion could initiate or reinforce the process of building a culture of shared responsibility for the 'well-being' of the scheme and the city's transport system in general (Nikitas et al., 2014a).

The past decade has seen a substantial increase in the perception of the bicycle as a realistic transport alternative to the car and bicycle sharing is now a reality which is clearly on the rise (dell'Olio et al., 2011). Around 900 public bicycle programmes currently operate around the world (Meddin and DeMaio, 2015), while many more are being planned. Nonetheless, the impact of bike sharing is still only modestly investigated by the existing literature. More research therefore is necessary for developing a theoretical and empirical understanding of how these systems could effectively contribute in facilitating active travel in urban societies.

The principal goal of the present paper is to look into the attitudes of people living in Gothenburg towards bicycle use in general and bike sharing in particular and explore the local scheme's 'success ingredients' and its potential to become a more well-embraced travel option in actual usage terms. This is therefore a paper with a strong focus on the public acceptance mechanisms of the scheme rather than a paper looking into current usage norms.

\section{Background}

Gothenburg is the second largest city in Sweden and the fifth largest between the Nordic countries with a city-based population of approximately 541145 citizens (Statistics Sweden, 2014). The overall residential population of Gothenburg's broader metropolitan area is close to one million, whereas Västra Götaland, the region to which Gothenburg belongs, has around 1.6 million inhabitants. The city is situated on the south-west coast of Sweden, hosts the largest harbour in Scandinavia and is approximately half way between the capital cities of Copenhagen and Oslo.

Gothenburg is a city providing a wide range of transport modes to its residents and visitors. Having a dedicated network of $160 \mathrm{~km}$ and 130 operating stations/stops, the blue iconic tram of the city is the largest light rail scheme in Scandinavia. Together with the city's bus network, which includes a four-line bus rapid transit scheme and express busses, trams form the basis of a public transport system and are responsible for 196 million trips per year (Trafikkontoret, 2014a). There are also daily boat and ferry services catering for the needs of a city that is defined (even in terms of its own name) by the river Göta. In early 2013, a roadpricing scheme was introduced in the city centre to regularly enforce, in some respect, modal change, while parking charges have been established for many years now in the central and residential areas of the city.

Gothenburg has Sweden's largest cycle network, with a total length of $793 \mathrm{~km}$. The cycle network consists of $486 \mathrm{~km}$ cycle paths, $150 \mathrm{~km}$ local cycle paths and $157 \mathrm{~km}$ mixed streets where the speed limit is $30 \mathrm{~km} / \mathrm{h}$ (Trafikkontoret, 2013). This emphasis on cycling infrastructure investments has been viable because, owing to the moderating influence of the warm Gulf Stream, Gothenburg enjoys milder weather conditions than most other cities with a similar high northern latitude. Gothenburg already has in place Styr \& Ställ, which is a self-service bike rental system, spread across 60 stations throughout the city centre with approximately 1000 bicycles. The system can be accessed 24 hours a day, seven days a week. It is available from 1 March to 31 December. Technical support is open during working hours every weekday. In order to access the system, customers have to subscribe to a 3-day pass (25 SEK), a season pass (75 SEK) or a special business subscription. The usage is free for the first $30 \mathrm{~min}$ as a means of promoting short-term rentals. Information about the location of each station and pick-up and drop-off availability in real-time is accessible by way of a free mobile application. The scheme is financed by the revenue generated from its users and from the commercial billboards placed throughout the city.

The scheme launched its operations in August 2010, consisting of 300 bicycles and 20 stations; by the end of its first season it had expanded to 500 bicycles in 40 stations. From 2012 onwards bike-sharing services can be integrated with the services provided 
by the Västtrafik card, which is the equivalent of a one-for-all public transport pass for Gothenburg, eliminating the need for a separate Styr \& Ställ card. In 2013 the number of rental stations increased to 57 and the number of bicycles to almost 1000. In 2014 three more stations opened and the duration of the season expanded to 10 months per year (i.e. the service was available from April to October initially).

\section{Research methodology}

A primarily quantitative questionnaire was administered containing 20 main questions organised in five parts referring to: the respondents' daily travel experience; their views on cycling; their attitudes towards public bicycles and Gothenburg's Styr \& Ställ; their real-life bike-sharing experiences from Styr \& Ställ; and their demographic characteristics. The thematic part regarding actual bike-sharing experience was set to have the respondents evaluating some selected attributes of the scheme. It was referring strictly to individuals that had used the public bicycles of Styr \& Ställ at least once. This was the only precondition for filling out a specific section of the questionnaire; all the other parts were open to every respondent.

It should be noted that four of the main questions each contained a number of sub-questions, so that the phenomena negotiated by the study could be described in a more complete way. Five-point Likert scales were used to record responses varying from 'strongly agree' to 'strongly disagree'. The questionnaire also employed a recruitment question for a potential follow-up study of a more qualitative character. Respondents answering 'yes' to this question had to provide their contact details. The time for fully completing the questionnaire was calculated to be approximately 10 to $15 \mathrm{~min}$ depending on whether the respondent was eligible to complete the bike-sharing experience section and keen to write down some additional comments on the topic at the end of the questionnaire.

Participation incentives and a survey introduction were used to improve the response rates. The main incentive was an entry into a prize draw for a new bicycle; the only prerequisite for taking part in this was the completion of the questionnaire and the provision of contact details. The preface of the questionnaire introduced the research project and explained that the terms 'public bicycles' and 'bike sharing' referred specifically to Styr \& Ställ. It also informed the likely respondents that there was not a 'usage of the system' precondition in place for answering the questionnaire (with the exception of the user experience section) and discussed why completing the survey could be a meaningful and timely task for them. The survey introduction also indicated that the respondents' submitted material would be used strictly for the purposes of academic research and would be handled and stored in a professional and confidential way.

The distribution of the questionnaire in Gothenburg was conducted by way of an online survey accessible from the official web page of Chalmers University of Technology. Circulating the online questionnaire was amplified by the use of social media and e-mail requests to specific e-mailing lists referring to some of the city's biggest employers such as: the City of Gothenburg, Volvo, Chalmers University of Technology and the University of Gothenburg. A hard-copy questionnaire distribution was not employed because of Gothenburg's high internet usage rates and the locals' relative exposure to online surveys. Financial constraints were also another reason for this one-dimensional distribution strategy. The final sample refers to 558 useable responses. For the thematic part of the questionnaire addressing public bicycle experience, 368 responses were collected. This meant that $65.9 \%$ of the study respondents had used the scheme at least once. However, since the study (and this paper) aimed to look beyond strict usage criteria, exploring broader public acceptance norms instead, most of the analysis is based on the whole sample of 558 respondents.

\section{Results and analysis}

The study's complete set of results aims to explore some of the attitudes that the residents of Gothenburg hold towards cycling in general and bike sharing in particular. These attitudes primarily reflect (directly or indirectly) public acceptability towards Styr \& Ställ and secondarily refer to the user experiences of the respondents that had actually used Styr \& Ställ at least once. This paper aims to focus on the first type of attitudes and only partially describe the other one in the final section of the analysis.

\subsection{Demographic characteristics}

Looking into the profile of the sample in terms of their demographic characteristics and later on in terms of their basic travel behaviour patterns is a key enabler for facilitating more meaningful comparisons between the respondents as part of the analytic process. These data could eventually allow the identification of particular groups (e.g. based on age or frequency of cycling) that could have specific group-related attitudinal issues.

Table 1 provides a synopsis of the demographic profile of the sample in terms of gender, age, type of household, education background and household income. The gender split of the sample was not very different from the city's gender split (50.03\% male, $49 \cdot 97 \%$ female according to Statistics Sweden, 2014). The age split, however, is not. It rather reflects the appeal and potential usefulness that the attitude object (i.e. bike sharing) could have on different ages. For example, people aged 60 and over who, in general, owing to more physical limitations, are far less likely to cycle, and therefore use bike sharing, did not participate in the survey in large numbers. This underrepresentation is in line, however, with similar cycling-related studies (e.g. Fishman et al. 2015; Pucher et al., 2011; Shaheen et al., 2012). Also the use of an online survey that was communicated heavily through social media applications explains the significantly higher number of respondents aged 20-29. This group, together with the 30-39 age group, consisted of the individuals most likely to self-report high frequency of cycling. Older people, although it should be acknowledged very few, were the respondents most likely not to cycle or bike share. The 


\section{Demographic characteristics Sample's specifics}

Gender

Male: $55 \cdot 97 \%$

Age

$$
\begin{aligned}
& <20: 2 \cdot 80 \% \\
& \text { 20-29: } 58 \cdot 21 \% \\
& \text { 30-39: } 22 \cdot 76 \% \\
& \text { 40-49: } 7 \cdot 46 \% \\
& \text { 50-59: } 7 \cdot 09 \% \\
& \text { 60-69: } 1 \cdot 31 \% \\
& >70: 0 \cdot 37 \%
\end{aligned}
$$

\section{Type of household}

$$
\begin{aligned}
& \text { Single: } 33 \cdot 58 \% \\
& \text { Couple: } 35 \cdot 45 \% \\
& \text { Family (with child): } 16 \cdot 04 \% \\
& \text { Family (parents): } 6 \cdot 72 \% \\
& \text { Sharing flat with others: } 5 \cdot 97 \% \\
& \text { Other: } 2 \cdot 24 \%
\end{aligned}
$$

Educational background

Elementary school: $0 \cdot 56 \%$
High school: $18 \cdot 47 \%$
Bachelor: $26 \cdot 12 \%$
Master: $41 \cdot 98 \%$
Doctorate: $5 \cdot 97 \%$
Other: $6 \cdot 90 \%$

Income (household)

$$
\begin{aligned}
& <20000 \text { SEK: } 37 \cdot 90 \% \\
& 20001-30000 \text { SEK: } 12 \cdot 01 \% \\
& 30001-50000 \text { SEK: } 15 \cdot 95 \% \\
& 50001-70000 \text { SEK: } 12 \cdot 76 \% \\
& 70001-100000 \text { SEK: } 8 \cdot 26 \% \\
& \text { >100 } 001 \text { SEK: } 2 \cdot 44 \% \\
& \text { Do not want to say: } 10 \cdot 69 \%
\end{aligned}
$$

Table 1. Demographic characteristics of the sample

correlation between age and frequency of cycling was statistically significant $\left(\chi^{2}=43 \cdot 293 ; \mathrm{df}=30 ; p<0 \cdot 05\right)$. The young age of the sample probably had an impact on the results collected.

\subsection{Daily travel experience}

This section reports on the respondents' daily travel experience when commuting in Gothenburg. Figure 1 illustrates the frequency with which the respondents use the different transport modes available in Gothenburg.

More than half of the respondents use a bicycle on a frequent basis, which is an over-representation of the average cycling engagement in Gothenburg. Cycling accounts for $7 \%$ of all trips made in Gothenburg, which is slightly lower than the national Swedish average of $9 \cdot 2 \%$ (Spolander, 2013). However, latest measurements revealed that the increase in the number of bicycle crossings from the bicycle monitoring stations of Gothenburg between 2012 and
2013 was historic, reaching 14\% (Trafikkontoret, 2014a). According to the same source, this increase is likely to be the result of the city's efforts to promote cycling, the introduction of a citycentre congestion charge and the good weather.

Table 2 summarises the results referring to the respondents' levels of driving licence holding, primary means of commuting to work or to their most frequent destination, main reason for making a mode selection, frequency of experiencing traffic congestion and the magnitude of difference in commuting between wintertime and summertime.

\subsection{Attitudes towards cycling}

Two more questions directly referring to bicycle ownership and the way in which people tend to use bicycles confirms that cycling is an integral part of Gothenburg's identity when it comes to commuting. Table 3 provides a summary of these results.

The next set of questions was designed to measure the attitudes regarding some basic attributes of cycling. A synopsis of these results is given in Table 4.

Overall, the respondents believed that cycling is a cost-saving, sustainable, pleasant and healthy travel option with a strong potential to reduce road traffic congestion. The vast majority of the respondents deemed riding a bicycle as a good travel alternative to a car for inner-city trips and as a time-saving transport mode. Nonetheless, many respondents were likely to consider cycling not particularly safe. It should be noted, nevertheless, that even for this issue the opinions were marginally positive on aggregate.

The respondents were clearly in favour of more cycling-related investments, something recognised even by the vast majority of people rarely $(80.5 \%)$ or never $(79 \cdot 5 \%)$ cycling $\left(\chi^{2}=58 \cdot 760\right.$; $\mathrm{df}=20 ; p<0 \cdot 05)$. However, the finding reflecting closer than any other the respondents' acceptance of the scheme was the one denoting their compliance with the notion that 'Styr \& Ställ is good for their city'. Even within the respondents who never or rarely used bikes, very few were found to believe that Styr \& Ställ was not a good scheme $(0 \%$ and $2 \cdot 5 \%$ expressed some form of disagreement, respectively). There were very few factors that had a statistically significant correlation with the attitude about the perceived goodness of Styr \& Ställ; namely the way in which (e.g. primary or alternative mode) respondents used the scheme $\left(\chi^{2}=38.345 ; \mathrm{df}=16 ; p<0.05\right)$ and age $\left(\chi^{2}=42 \cdot 292 ; \mathrm{df}=24\right.$; $p<0 \cdot 05)$. More specifically, people that self-reported that they never use bike sharing (not even as a secondary alternative) were more likely to express disagreement with the notion that 'Styr \& Ställ is good for Gothenburg', but again these were very few. In terms of age, people in the age brackets $40-49$ and 50-59 were the only groups in which some participants expressed negative attitudes to this notion. Figure 2 illustrates the attitudes referring directly to the public acceptance of the scheme and towards cycling-related investments in broader terms. 


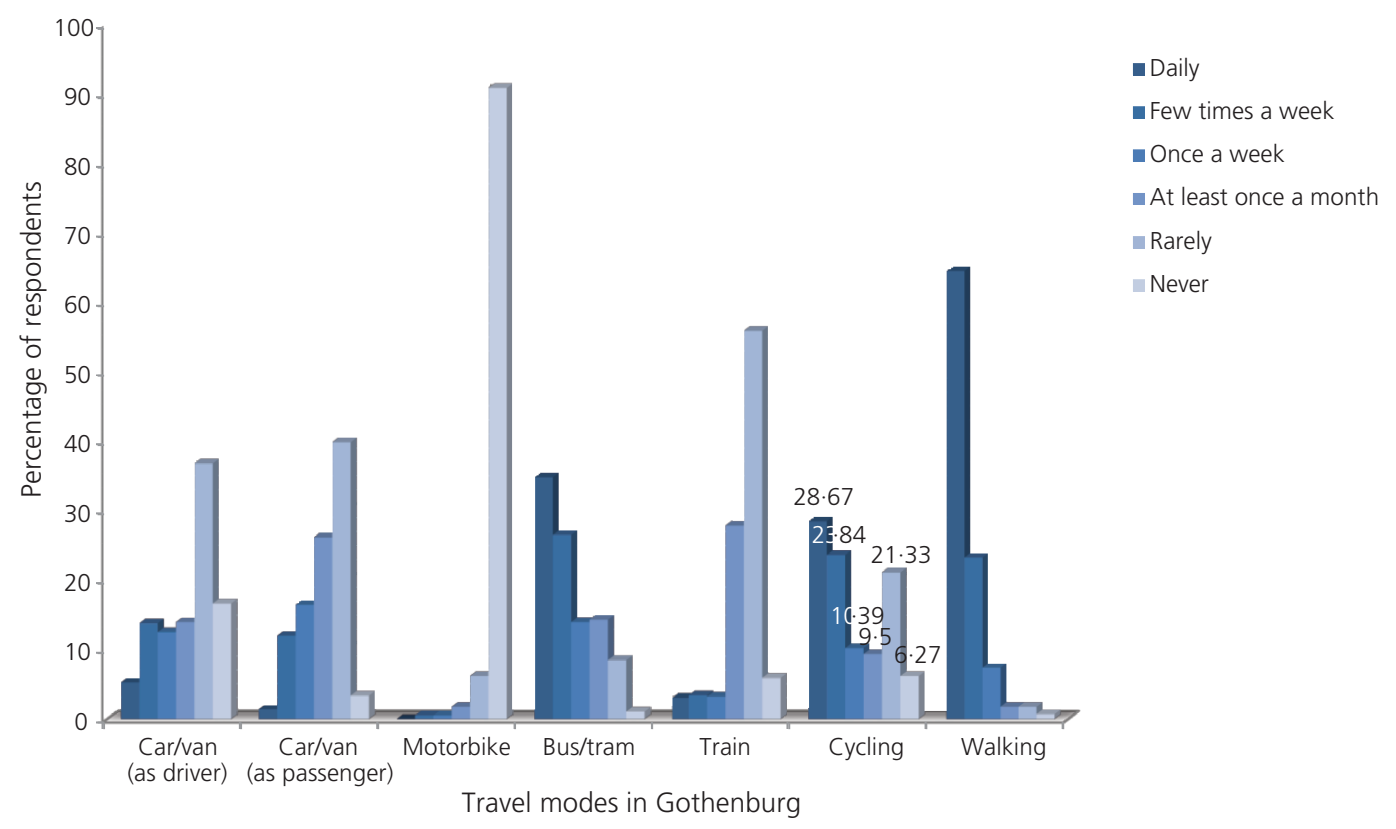

Figure 1. Respondents' frequency of using certain transport

\subsection{Attitudes towards bike-sharing}

This set of results refers directly to the main theme of the study. Table 5 summarises the frequency and the way in which the respondents have been using Styr \& Ställ from its very first complete season of operation in 2011 until the end of 2014. This was an intentional feature of the study, meaning to explore whether people were more likely to use the scheme over time, as this was gradually transforming to an established part of the city's transport identity. It should be noted that the validity of these results depends on how precisely the respondents could remember their travel choices in past years, which could have been a cognitively challenging task for some.

The results denote that although the scheme had 24640 season subscribers in 2013 and facilitated 420500 trips, more than doubling the scheme-related trips compared to 2012 (Trafikkontoret, 2014b, there are too many people that have not taken an active part in its expansion. The vast majority of the respondents self-reported small engagement with Styr \& Ställ. The results, however, also indicate that there is a small (percentage-wise) but clear, nonetheless, annual increase in the number of people using the scheme. The most important increase refers to the people using Styr \& Ställ as their secondary travel alternative that has been doubled over the accessed four-year usage span and, at the end of 2014, applied to more than one fifth of the sample.

Another important result referring to the frequency with which the respondents used the fleet of Styr \& Ställ was that the people who self-reported some consistent but not daily level of bicycle usage (i.e. 'few times a week' and 'once a week') were more likely to document that they bike shared at least once or a few times per week than the respondents cycling every day and those cycling rarely or never. This indicates perhaps that this should be the group of people that policy-makers could be targeting first for increasing ridership. These are the people who, on the one hand, like to cycle regularly, but are not the hard-core type of daily cyclists who might be fixated with their own bicycle, and on the other hand appreciate what is offered by Styr \& Ställ. This was a statistically significant result $\left(\chi^{2}=63 \cdot 182 ; \mathrm{df}=20\right.$; $p<0 \cdot 05)$.

The results reported in Table 6 show that the respondents were very likely to recognise a number of societal benefits that could be linked to the programme. This indicates that the respondents thought that Styr \& Ställ and bike sharing in general, even if it was not useful per se to the majority of them, was a scheme with strong pro-social potential that could be a viable alternative for the city. Therefore, Styr \& Ställ's 'option value', which refers to the value that is placed on private willingness to pay for maintaining or preserving a public asset or service even if there is little or no likelihood of the individuals actually ever using it, could be eventually higher since the significant current expenditure referring to the scheme's expansion did not generate negative attitudes towards its existence or importance for the city.

Overall, the respondents recognised that the scheme had a beneficial influence on the city. The vast majority of them agreed that Styr \& Ställ is a sustainable mode that could mitigate road traffic problems, complement other means of public transport and car usage (when a car trip cannot be avoided), offer an inexpensive transport option, promote wellbeing, make cycling a more popular travel choice and reduce people's reliance on automobiles. 
The paradox of public acceptance of bike

sharing in Gothenburg

Nikitas, Wallgren and Rexfelt
Daily travel experience

Licence holding

Primary means of travelling

to most frequent destination

Primary factor for choosing

transport mode
Respondents' answers

Yes: $84 \cdot 41 \%$

No: $15 \cdot 59 \%$

Car (driver): $5 \cdot 73 \%$

Car (passenger): 0.90\%

Motorcycle: 0.0\%

Bus: $37.46 \%$

Train: $3.94 \%$

Cycling: $30 \cdot 47 \%$

Walking: $21 \cdot 51 \%$

Cost: $14 \cdot 49 \%$

Comfort: $22 \cdot 61 \%$

Availability: $28 \cdot 60 \%$

Time: $26 \cdot 12 \%$

Environmental awareness:

$7 \cdot 18 \%$

Frequency of finding oneself in congestion

Travel choices between wintertime and summertime
Daily: $1 \cdot 08 \%$

Few times a week: $4.30 \%$

Once a week: $5 \cdot 38 \%$

At least once a month:

$8 \cdot 24 \%$

Rarely: $50 \cdot 54 \%$

Never: $30 \cdot 47 \%$

Very different: $34 \cdot 39 \%$

Somewhat different:

$35.50 \%$

Same: $30 \cdot 11 \%$
Table 2. Respondents' daily travel experience

There was also the question of looking again into the 'perceived overall goodness' of Styr \& Ställ asking the respondents to evaluate the notion that the scheme was "not good for their city'. Perceived goodness was hypothesised by the authors to be the most direct indicator of the scheme's public acceptance (in
Bicycle-related norms Respondents' answers

Bicycle ownership $\quad$ Yes: $78.66 \%$

No: $21 \cdot 34 \%$

Way of utilising cycling Main travel mode: $33 \cdot 27 \%$

Main travel alternative: $19 \cdot 17 \%$

Secondary travel alternative: $24 \cdot 77 \%$

Exercise and joy: $8.68 \%$

Do not cycle: $14 \cdot 10 \%$

Table 3. Respondents' bicycle ownership and type of bicycle usage

line with studies such as Nikitas et al., 2011) so this result was of significant importance. The general disagreement that was recorded (only $2 \cdot 5 \%$ of the respondents supported the notion) validates the result reported in the previous section suggesting that Styr \& Ställ is good for Gothenburg (only $1 \cdot 4 \%$ of the respondents did not support that earlier statement).

Another set of more focused questions captured the respondents' attitudes towards specific qualities of Styr \& Ställ. The respondents did not seem to be motivated by the possibility of having electric bicycles introduced in Styr \& Ställ's fleet, although Gothenburg's hilly topography and some people's inability or dislike to engage in an activity requiring physical effort could have been addressed in this way. Another notable finding is that many of the respondents found the bicycles and the bike rental stations not particularly attractive, although on aggregate this result was positive. Most of the respondents believed that public bicycles offer a viable and popular service for the city that needs to be expanded in more destinations. The latter result confirms once more that the majority of the respondents were in favour of further investments in Styr \& Ställ, this time for its expansion. Table 7 summarises these results.

Looking into the reasons that made some respondents reluctant to bike share more regularly or bike share at all was another theme that was examined. The respondents were asked to choose up to two different factors that they considered as potential

Mean support for the statements below

(when $-2=$ strongly disagree and 2 = strongly agree)

Attitudes regarding cycling's basic attributes for the user

Cycling is sustainable Cycling is time-saving

1.83 (SD 0.48)

1.03 (SD 0.94)

Cycling is cost-saving

1.68 (SD 0.64)

Cycling is safe

0.37 (SD 0.99)

Attitudes regarding cycling's broader value

Cycling can improve public Cycling can reduce traffic health congestion

1.75 (SD 0.54)
Cycling is a pleasant travel experience

$1 \cdot 51(\mathrm{SD} 0 \cdot 72)$
Cycling is the best inner-city transport alternative 1.05 (SD 1.06)

Table 4. Attitudes towards cycling 
The paradox of public acceptance of bike

sharing in Gothenburg

Nikitas, Wallgren and Rexfelt

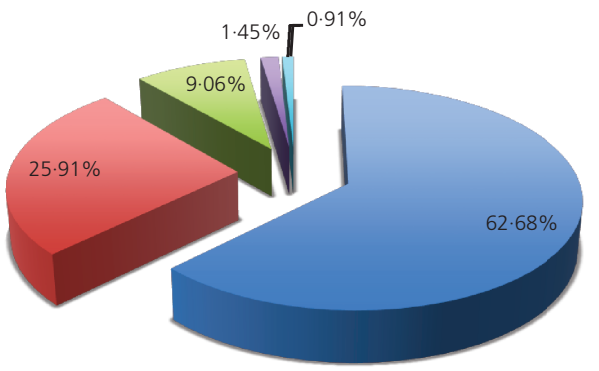

(a)

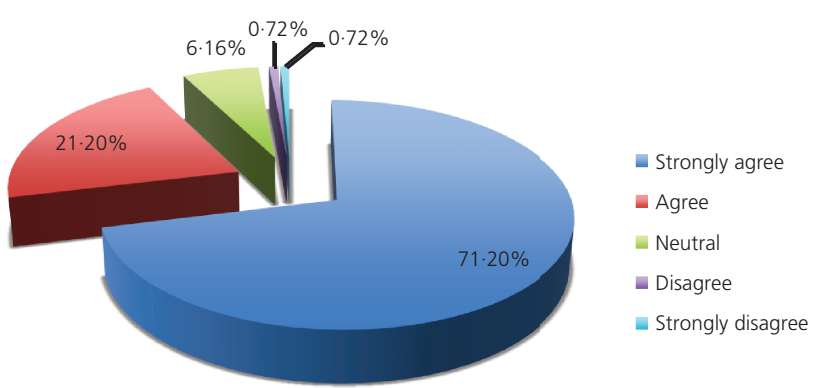

(b)

Figure 2. Public acceptance of cycling-related investments and Styr \& Ställ: (a) more bicycle-related investments are necessary in Gothenburg; (b) public bicycles (Styr \& Ställ) are good for Gothenburg

barriers in using Styr \& Ställ. Approximately two-fifths of the respondents self-reported that they are not interested in bikesharing since they have their own bicycle. The second most important reason for this reluctance, and one that is actually associated with the scheme per se, was the lack of good bikesharing infrastructure. This description was addressing themes referring to cycling infrastructure such as dysfunctional or not user-friendly bike rental stations. Limited road safety and Gothenburg's inappropriateness (e.g. hilly topography, bad weather conditions) for hosting such a scheme were two more barriers that were highlighted by some respondents. Poor bicycles and price-related issues were not among the most popular barriers. 'Other reasons', referring to individuals' special reasons for not bike sharing, was also a frequent answer. These reasons spanned from issues such as the 'need to have special bikes provided for special populations instead of a standard bike for all' to issues such as the 'unavailability of bikes or parking spots at the rental stations due to the scheme's popularity'. It should be noted that most of these answers were so unique that they could not be grouped into meaningful categories. Figure 3 provides graphical information about the participants' responses.

Fishman et al. (2012) had a similar question in a study about Melbourne's public bicycle programme. They asked their survey respondents to nominate the major barrier preventing the widespread use of the scheme. The most popular answer was 'helmet issues' (it is obligatory to wear a helmet when bike sharing in Australia) with $61 \%$, followed by 'bad weather' with a mere, in comparison, $16 \%$. Since 'helmets' were rarely mentioned by the respondents in Gothenburg (they are included in the 'other reasons' category) and 'weather conditions' was not per se as favourable as an answer either, it can be argued that each scheme has a unique set of issues closely related with the city-host's realities that could be a recipe for success or failure.

\section{Bike-sharing norms}

2011

Frequency of using Styr \& Ställ

Daily:

Few times a week:

Once a week:

At least once a month:

Rarely:

Never:

Main travel mode:

Main travel alternative:

Secondary travel alternative:

Exercise and joy:

Do not use:
$0.19 \%$

$0.37 \%$

$1 \cdot 30 \%$

$0.93 \%$

$5.95 \%$

$91 \cdot 26 \%$

2011

$0.19 \%$

$1 \cdot 12 \%$

$9.85 \%$

$0.74 \%$

$88 \cdot 10 \%$
2014

$0.74 \%$

$6 \cdot 88 \%$

$3.53 \%$

$2.42 \%$

$9.67 \%$

$76.77 \%$

$85.82 \% \quad 73.79 \%$

2014

$2 \cdot 84 \%$

$5.48 \%$

$21.55 \%$

$0.38 \%$

$69 \cdot 75 \%$

Table 5. Frequency and way of using Styr \& Ställ over the years 
Mean support for the statements below

(when $-2=$ strongly disagree and $2=$ strongly agree)

Attitudes regarding bike-sharing's potential benefits

Styr \& Ställ is good for...

...promoting a green and

...improving road traffic conditions in terms of congestion identity 1.35 (SD 0.76) $1 \cdot 25$ (SD 0.83)

Styr \& Ställ is good for... ...promoting healthy living ...providing an inexpensive
transport mode

$1 \cdot 16(S D 0 \cdot 89)$ $1 \cdot 41($ SD 0.82) ...making's people travel behaviour increasingly less car dependant

...making bicycle use more popular and publicly accepted ...complementing public transport and car usage $1 \cdot 28$ (SD 0.85)

Styr \& Ställ is not good $-1 \cdot 76(S D 0.66)$

Table 6. Attitudes towards Styr \& Ställ reflecting pro-social potential

\subsection{Attitudes towards bike sharing reflecting user experiences}

The final set of results refers to the smaller sample of 368 respondents that actually had used Styr \& Ställ at least once and therefore were eligible to submit their attitudes towards some user-experience-related evaluation items. Among this group of respondents, $78 \cdot 6 \%$ owned a bicycle, $49 \cdot 6 \%$ of them used bicycles as their primary or secondary travel alternative in comparison to $31.4 \%$ using bicycles as their main modal choice and $91.9 \%$ believed that Styr \& Ställ was a good scheme. The 'ownership' and 'perceived goodness' figures were almost identical to those of the extended sample (i.e. $78 \cdot 7 \%$ and $92 \cdot 4 \%$, respectively), while the 'way of using a bicycle' statistics were very comparable too (as reported in Table 3).
The option 'neutral' was the respondents' most likely answer for each of the five statements of this thematic unit. This is why none of the figures demonstrating 'mean support for the statements' recorded in Table 8 was particularly positive or negative.

\section{Discussion}

With the growing interest in active travel as a solution to physical inactivity, urban air pollution and climate change (de Nazelle et al., 2011), it is important to recognise the complexity of the road-users' interactions with the engineering or policy-related interventions supporting sustainable transportation and the need to study them thoroughly. This is a prerequisite for implementing or reforming, when these already exist, active travel support mechanisms so that they could be truly embraced by their

Mean support for the statements below

(when -2 = strongly disagree and 2 = strongly agree)

Attitudes regarding Styr \& Ställ's specific qualities

I believe that...

...public bicycles provide ...public bicycles have ....public bicycles should be available to more a viable service for been very popular so far areas in Gothenburg

Gothenburg

1.69 (SD 0.56)

$1.09($ SD 0.82)

$1 \cdot 50($ SD 0.72)

..the bicycles used by Styr \& Ställ are attractive

$0.60($ SD 0.97)

I believe that...

...the bicycle stations used by Styr \& Ställ are attractive 0.74 (SD 0.84)

...the bicycles of Styr \& Ställ are everywhere in the city $-0.48($ SD 1.08)
... if some electric bicycles will be introduced to the programme I might be more likely to use Styr \& Ställ $-0 \cdot 16$ (SD 1.34) ...cycling and public bicycles constitute the future for greener cities 1.44 (SD 0.75)

Table 7. Attitudes towards some of the specific qualities of Styr \& Ställ 
Engineering Sustainability

Volume 169 Issue ES3
The paradox of public acceptance of bike

sharing in Gothenburg

Nikitas, Wallgren and Rexfelt

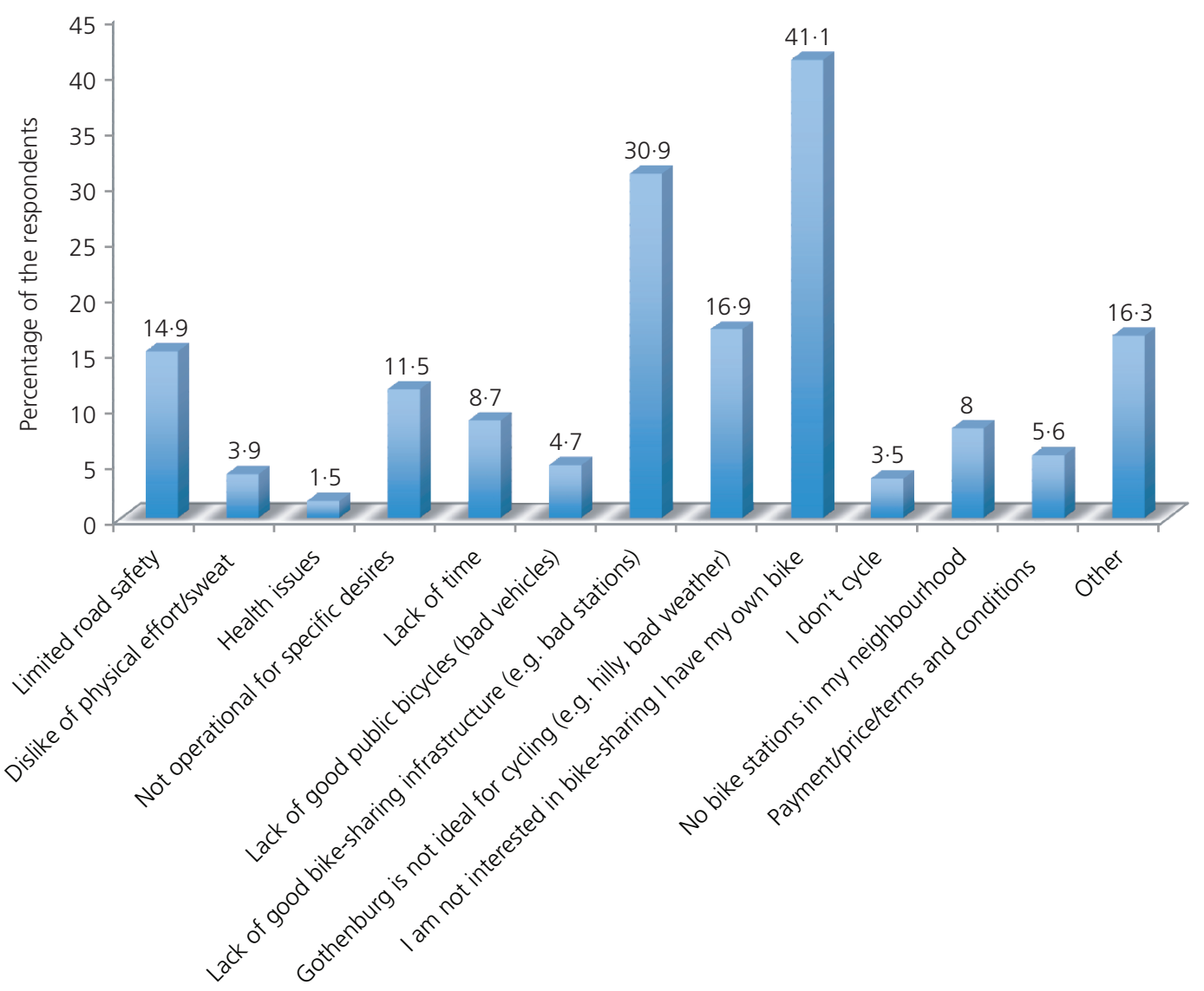

Figure 3. Reasons for not using bike sharing more regularly or at all

respective urban societies, especially in cases as novel and emerging as bike sharing. Understanding the mechanisms behind public acceptability is therefore a major first step in the process of providing for a potentially successful scheme.

The public bicycle, although still a relatively new mode of transport, has many positive characteristics in favour of its exploitation and integration on a much broader scale (Bordagaray et al., 2012) and has in theory at least the potential to be easily and widely acceptable. This is because bike sharing has had profound effects on creating a larger cycling population, increasing transit use, decreasing greenhouse gases and improving public health (DeMaio, 2009); or at least as Fishman et al. (2014) more moderately suggest 'implicit or explicit in the calculation of

Mean support for the statements below

(when -2 = strongly disagree and 2 = strongly agree)

Attitudes based on actual bike-sharing experience

I believe that...

...the bicycles of Styr \& Ställ are

comfortable

0.46 (SD 0.76)

...Styr \& Ställ is easy to use (uncomplicated) 0.57 (SD 0.93)
... the bicycles of Styr \& Ställ are always available in the station I need them 0.22 (SD 0.93)
...Styr \& Ställ can be better if electric bicycles will be introduced in addition to the conventional ones $0 \cdot 10($ SD 1.14)
...Styr \& Ställ has serious flaws that should be addressed

$-0.70($ SD 0.94)

Table 8. Attitudes towards Styr \& Ställ based on actual user experience 
public bicycle's benefits are assumptions regarding the modes of travel (i.e. car trips) replaced by bike share journeys'.

This paper, however, does not seek to repeat a discussion found elsewhere about the merits of bicycling in general or bike sharing in particular, but rather aims to identify and discuss road-user attitudes towards Gothenburg's bike-sharing scheme and with them some of the lessons learnt by a seemingly successful scheme and some of the opportunities that still exist. Attitudes are employed as means that affect and reflect public acceptance, and for a limited number of questions user experience, while travel behaviour patterns have also been recorded. It should be noted that a detailed spatial analysis of the dataset was beyond the scope of the present study.

Styr \& Ställ is a system that has gone from 300 public bicycles distributed in 20 stations operating strictly from April to October to 1000 bicycles in 60 stations available from March to December in less than five years. Furthermore, a customer survey conducted in December 2013 suggested that, at the time, 93\% of users were satisfied with it (Trafikkontoret, 2014b), while perhaps more importantly this paper suggests that $92 \cdot 4 \%$ of the respondents believe that Styr \& Ställ is good for Gothenburg. This success is not as straightforward and easy to read, replicate or even maintain, as it might seem.

Despite the fact that around 900 schemes operate around the world, Meddin and DeMaio (2015) also list as many as 115 public bicycle schemes that ceased their operations after failing to be adopted by their respective urban societies. Moreover, there are many bike-sharing programmes that, although they do not seem to face any danger of being terminated yet, are severely underused and therefore their potential to facilitate active travel is somewhat wasted. Fishman et al. (2013) reported substantial differences in the usage rates of bike-share schemes globally, with most of them varying from around three to eight trips per bicycle per day, but some of them facilitating as few as 0.3 trips per bicycle per day.

In many cases 'low usage rates' do not constitute the only or main problem of a bike-sharing scheme; other 'success ingredients' might also be missing. Stockholm City Bikes, for example, which could be highly comparable to Styr \& Ställ, suffered from sluggish expansion; only half of the planned 160 stations were in place after four years because of limited urban space, a slow and complicated planning process, political unwillingness to put street parking at bike-sharing's disposal, and other infrastructure projects being prioritised (Büttner et al., 2014). Nine years after their launch, Stockholm City Bikes, with 140 stations operating only from 06:00 to 22:00 and between April and October, are still noticeably short of the initial plans. This is a different story from that of Styr \& Ställ, where strong political support for the scheme per se, but also a historical tradition in investing in cycling infrastructure, made a continuous and aggressive expansion possible.
Specific hypotheses, each reflecting how the respondents viewed cycling and bike-sharing, were examined for this study. The majority of them, at least at the aggregate level, provide strong evidence that people hold positive attitudes towards the scheme and assign positive attributes to cycling in general and to bike sharing in particular. Even the respondents that self-reported small or no engagement with Styr \& Ställ, thus far, tended to be positive towards the scheme and recognised its potential to benefit the city.

This means that the introduction and vast expansion of Styr \& Ställ was not viewed as a measure favouring a particular roaduser segment (i.e. those interested to bike share) over other people not using this mode of transport. This is important considering that bike sharing is not perhaps ideal for every member of an urban society since it cannot accommodate storage or family needs, may not be a viable choice under bad weather conditions and for long distances, might not be useful for people already owning bicycles and perhaps, more importantly, its embracement requires an adequate level of physical endurance that excludes mobility-challenged individuals from using it. At the same time, although not as costly as other road transport infrastructure investments, bike sharing has a substantial start-up and maintenance cost and takes up valuable road space. An example of the latter is that recently the city of New York required reimbursement from the operators of the newly arrived local Citi Bike for lost parking revenue.

This indicates that, although most of the respondents do not see Styr \& Ställ as an investment useful to them personally, they agreed that it was a scheme with a strong pro-social potential; a scheme that was so good that, according to them, it had to expand in more areas around Gothenburg. Knowing about the acceptance of bike-sharing, among wider audiences than its users, could perhaps allow a legitimate hypothesis about Styr \& Ställ's 'option value'. This could be placed even higher than it is today since, according to the vast majority of the 558 residents of Gothenburg that took part in this study, Styr \& Ställ is a worthwhile project. This is something that could be particularly meaningful for policy-makers if they seek to invest more in the scheme.

However, this 'public acceptance' has not yet transformed into high usage rates. Almost three quarters of the participants (78.5\% of the people owning a bicycle and $70 \%$ of those not owning one) do not use the scheme today. This clearly denotes that, despite the 420000 recorded bike-sharing trips in 2013, there is still a huge potential for new ridership. The study identified some of the reasons associated with the respondents' reluctance to bike share. A major reason for not bike sharing, at least for $41 \cdot 1 \%$ of the respondents in general and $52 \cdot 1 \%$ of the bike owners in particular, is that they already have a bicycle. Despite the fact that these people may not be viewed as the main target audience for any programme that is primarily aiming to facilitate travel behaviour change $(76 \cdot 1 \%$ of them already cycle at least a few times per week), perhaps focused information about the scheme's potential to provide a valid 
alternative to them, when for some reason using their own bike is not an option, could increase the scheme's usage rates.

This is not a recommendation that aims to disengage regular cyclists from using their own private bicycles in favour of bike sharing; such a shift is not realistic since: (a) ownership and instant availability is an appealing feature to many cyclists; $(b)$ the doorto-door service that a private bicycle offers cannot be fully replaced by any current bike-sharing scheme; $(c)$ there is no real value to society since none of the adverse car-related impacts can be lessened from such a transition. Nonetheless, regular cyclists can embrace bike-sharing as a complement that will only strengthen their habitual cycling behaviour allowing them to cycle even in cases when their private bicycle may not be a viable option for them. For example, there are some occasions when cyclists could be reluctant to use their own bicycles in certain neighbourhoods, fearing bike theft or other cases where their bicycles might be temporarily unavailable owing to maintenance reasons.

The second most important barrier to bike sharing was considered by $30.9 \%$ of the respondents to be a lack of good bike-sharing infrastructure; something in line with the existing literature. According to Fishman et al. (2012) a lack of contiguous bicycle infrastructure has been identified as a barrier to bicycling in general and to bike sharing in particular by many studies. Daley et al. (2007) suggested that themes centred on safety concerns, with the absence of good cycling infrastructure being one of them, are among the prime obstacles in adopting cycling. Another form of these safety concerns as addressed by Daley et al. (2007) seemed to be the reason that another $14.9 \%$ of the respondents do not bike share; this is the perception that limited traffic safety is provided for cyclists. These two safety-oriented reasons have been thoroughly studied and linked to each other by Nikitas et al. (2014b) for the means of two different public bicycle schemes, with one being Styr \& Ställ.

Another $8 \%$ of the study participants did not use the scheme because they lived in a neighbourhood without a hire station. The proximity of residential addresses to docking stations appears to have a powerful influence over propensity to use a bike-share programme as Fuller et al. (2011) recorded in their study in Montreal, Canada. Bachand-Marleau et al. (2012) also suggested that the potential of bike-sharing systems can be maximised by increasing the number of docking stations in residential neighbourhoods. Therefore, Styr \& Ställ could increase its annual subscribers if it expands further away from the city centre in places such as the residential areas in the island of Hisingen or the Science Park of Lindholmen, which hosts 21000 people working or studying and is five minutes away from the main city by water transport. Gothenburg's hilly topography was another barrier that was identified by the respondents, but a potential solution (the employment of electric bicycles) was not particularly supported nonetheless.

The results referring to the progression of the scheme's usage rates over a four-year span (from 2011 to 2014), despite their significantly low nature, especially when compared to the results meaning to capture public acceptance, indicate that there is a small but clear annual increase in the number of people using the scheme. This means that the transition from simply having a positive attitude towards the scheme to actually using it is a slow process; a process that takes time. The biggest usage increase referred to those respondents that self-reported using Styr \& Ställ as their secondary travel alternative. Their percentage has been doubled over the accessed four-year usage span referring in 2014 to more than a fifth of the sample. Also respondents who selfreported some regular but not daily level of cycling activity were more likely than the respondents cycling on a daily basis and the ones using a bike rarely or never, to document that they bikeshared at least once or a few times per week. It can be hypothesised thus that if local policy-makers need to increase the ridership of Styr \& Ställ they should start by advocating (or supporting) its appeal, predominately, as a good alternative solution for commuting (and not a primary one) to people that have some engagement with cycling already but are not yet everyday cyclists.

It should be acknowledged that the sample over-represented people cycling regularly and was particularly young in age. This could be partially a product of the online type of survey that was administered (technology-challenged people could not have been engaged as easily), but it was also the result of the 'attitude object' being more appealing to certain segments of the population that could eventually be more actively engaged with the use of Styr \& Ställ. It should be noted, however, that these people have, in general, significantly more insights to offer on cycling-related activities than people who do not use bicycles and might not consider adopting bike sharing in reality. Fishman et al. (2015) actually provide evidence that could, to some degree, support this justification for the over-representation of younger age groups, at least, by suggesting that age could be a significant predictor of bike-sharing membership (and thus interest in bike sharing) with people aged 18 to 34 being significantly more likely to subscribe to a public bicycle programme than other age groups.

As is generally the case in respect of first-stage exploratory studies, further research would be useful for an in-depth examination of the reasons that make people's attitudes so positive towards a scheme that a lot of them do not use at all. Some of these studies have been already planned by the authors for the near future and will have a more qualitative focus. A similarly structured study, examining attitudes in Drama, Greece for the eventual implementation of a small bike-sharing scheme, has also been conducted.

\section{Conclusions}

Investing in a transport innovation that facilitates increased bicycle usage by rebranding something as conventional as urban cycling in a way that integrates the concept of the shared resource economies, is a powerful tool for policy-makers and engineers looking to promote active transportation. The importance of this 'investment' is magnified if this bike-sharing intervention has the potential to be an iconic transport addition, which benefits the image of the city-host and at the same time is publicly acceptable 
even from people that may not use it. This study looked at the case of Styr \& Ställ in Gothenburg by examining the attitudes, travel behaviours and user experiences (the latter only when applicable) of 558 survey respondents. Perhaps, the missing link for classifying Styr \& Ställ as 'a major success' is the fact that it has not been consistently used by the majority of the respondents, despite continuous investments in its expansion. Nonetheless, the scheme is well accepted and appreciated even by the people that do not seem likely to ever use it. The key to explain this paradox could be Styr \& Ställ's pro-social value since it was recognised, by the vast majority of the respondents, as a scheme benefiting society as a whole in many ways (i.e. reducing road traffic congestion, improving healthy living, being an inexpensive alternative for commuting within the city, etc.). The fact is that by expanding so much in so little time, Styr \& Ställ became instantly recognisable to anyone (even to non-users) commuting within central Gothenburg and this has been perhaps central for solidifying this pro-social character. The paper also provides tentative evidence that potentially this public acceptance could be translated into actual usage of the scheme, but this transition might need more time and further investments. Finally, looking at the bigger picture, this work could be a source of guidance to other cities, highlighting barriers and determining success, in setting up or expanding bike-sharing schemes.

\section{Acknowledgements}

The authors would like to acknowledge the Division of Design \& Human Factors and the Department of Product and Production Development of Chalmers University of Technology for supporting financially the current study.

\section{REFERENCES}

Bachand-Marleau J, Lee BHY and El-Geneidy AM (2012) Better understanding of factors influencing likelihood of using shared bicycle systems and frequency of use. Transport Research Record 2314: 66-71.

Beroud B and Anaya E (2012) Private interventions in a public service: An analysis of public bicycle schemes. In Cycling and Sustainability (Transport and Sustainability) (Parkin J (ed.)). Emerald Group Publishing, Bingley, UK, vol. 1, pp. 269-301.

Bordagaray M, Ibeas A and dell'Olio L (2012) Modeling user perception of public bicycle services. Procedia - Social and Behavioral Sciences 54: 1308-1316.

Büttner J, Mlasowsky H, Birkholz T et al. (2014) Optimising Bike Sharing in European Cities: A Handbook. Intelligent Energy Europe, European Commission.

Daley M, Rissel C and Lloyd B (2007) All dressed up and nowhere to go? A qualitative research study of the barriers and enablers to cycling in inner Sydney. Road \& Transport Research: A Journal of Australian and New Zealand Research and Practice 16(4): 42-52.

de Nazelle A, Nieuwenhuijsen MJ, Anto JM et al. (2011) Improving health through policies that promote active travel: a review of evidence to support integrated health impact assessment. Environment International 37(4): 766-777.
dell'Olio L, Ibeas A and Moura JL (2011) Implementing bikesharing systems. Proceedings of the Institution of Civil Engineers - Municipal Engineer 164(2): 89-101.

DeMaio P (2009) Bike-sharing: history, impacts, models of provision, and future. Journal of Public Transportation 12(4): 41-56.

Fishman E, Washington S and Haworth N (2012) Barriers and facilitators to public bicycle scheme use: a qualitative approach. Transportation Research Part F: Traffic Psychology and Behaviour 15(6): 686-698.

Fishman E, Washington S and Haworth N (2013) Bike share: a synthesis of the literature. Transport Reviews 33(2): 148-165.

Fishman E, Washington S and Haworth N (2014) Bikeshare's impact on car use: evidence from the United States, Great Britain and Australia. Transportation Research Part D: Transport and Environment 31: 13-20.

Fishman E, Washington S, Haworth N and Watson A (2015) Factors influencing bike share membership: an analysis of Melbourne and Brisbane. Transportation Research Part A. Policy and Practice 71: 17-30.

Fuller D, Gauvin L, Kestens Y et al. (2011) Use of a new public bicycle share program in Montreal, Canada. American Journal of Preventive Medicine 41(1): 80-83.

Goodman A, Green J and Woodcock J (2014) The role of bicycle sharing systems in normalizing the image of cycling: an observational study of London cyclists. Journal of Transport and Health 1(1): 5-8.

Maibach E, Steg L and Anable J (2009) Promoting physical activity and reducing climate change: opportunities to replace short car trips with active transportation. Preventive Medicine 49(4): 326-327.

Meddin R and DeMaio P (2015) The Bike-sharing World Map. See http://www.bikesharingworld.com (accessed 07/09/2015).

Midgley P (2011) Bicycle-sharing Schemes: Enhancing Sustainable Mobility in Urban Areas. United Nations, New York, NY, USA. See http://www.un.org/esa/dsd/resources/ res_pdfs/csd-19/Background-Paper8-P.Midgley-Bicycle.pdf (accessed 26/11/2014).

Nikitas A, Avineri E and Parkhurst G (2011) Older people's attitudes to road charging: are they distinctive and what are the implications for policy? Journal of Transportation Planning and Technology 34(1): 87-108.

Nikitas A, Wallgren P and Rahe U (2014a) Public bicycles: how the concept of human-oriented 'mobility sharing' technology can influence travel behaviour norms and reshape design education. In Proceedings of the E\&PDE 2014 16th International Conference on Engineering and Product Design, University of Twente, The Netherlands (Bohemia E, Eger A, Eggink W et al. (eds)). The Design Society, Bristol, UK, pp. 159-164.

Nikitas A, Michalakopoulos N and Wallgren P (2014b) Bikesharing: is safety an issue adversely affecting its potential for being embraced by urban societies? Proceedings of the $3 \mathrm{rd}$ International Cycling Safety Conference, Gothenburg, Sweden, 18-19 November. 
Engineering Sustainability

Volume 169 Issue ES3
The paradox of public acceptance of bike

sharing in Gothenburg

Nikitas, Wallgren and Rexfelt
Pucher J, Dill J and Handy S (2010) Infrastructure, programs, and policies to increase bicycling: an international review. Preventive Medicine 50(Supplement): 106-125.

Pucher J, Buehler R and Seinen M (2011) Bicycling renaissance in North America? An update and re-appraisal of cycling trends and policies. Transportation Research Part A: Policy and Practice 45(6): 451-475.

Raviv T, Tzur M and Forma IA (2013) Static repositioning in a bike-sharing system: models and solution approaches. EURO Journal on Transportation and Logistics 2(3): 187-229.

Shaheen S, Guzman S and Zhang H (2010) Bikesharing in Europe, the Americas, and Asia. Transportation Research Record 2143: 159-167.

Shaheen S, Martin E, Cohen AP and Finson R (2012) Public Bikesharing in North America: Early Operator and User Understanding. Mineta Transportation Institute, San Jose, CA, USA.
Sheller M and Urry J (2000) The city and the car. International Journal of Urban and Regional Research 24(4): 737-757.

Spolander K (2013) Cykling i Sverige - En studie av variation mellan regioner och kommuner. Spolander Consulting, Stockholm, Sweden.

Statistics Sweden (2014) See http://www.scb.se/en_/ (accessed 27/ 08/2015).

Trafikkontoret (2013) En sammanfattning av årets cykelförbättringar Göteborg. Göteborgs Stad Trafikkontoret, Gothenburg, Sweden (in Swedish).

Trafikkontoret (2014a) Trafik- och resandeutveckling 2013. Göteborgs Stad Trafikkontoret, Gothenburg, Sweden (in Swedish).

Trafikkontoret (2014b) Cykelåret: En sammanfattning av årets cykelförbättringar 2013. Göteborgs Stad Trafikkontoret, Gothenburg, Sweden (in Swedish).

Vergragt PJ and Brown HS (2007) Sustainable mobility: from technological innovation to societal learning. Journal of Cleaner Production 15(11-12): 1104-1115.

\section{WHAT DO YOU THINK?}

To discuss this paper, please submit up to 500 words to the editor at journals@ice.org.uk. Your contribution will be forwarded to the author(s) for a reply and, if considered appropriate by the editorial panel, will be published as a discussion in a future issue of the journal.

Proceedings journals rely entirely on contributions sent in by civil engineering professionals, academics and students. Papers should be 2000-5000 words long (briefing papers should be 1000-2000 words long), with adequate illustrations and references. You can submit your paper online via www.icevirtuallibrary.com/content/journals, where you will also find detailed author guidelines. 